\title{
Perubahan kalor jenis campuran bahan mortar dengan penambahan pasir besi
}

\author{
Hartono*, Sugito dan Farzand Abdullatif \\ Program Studi Fisika, Fakultas MIPA, Universitas Jenderal Soedirman \\ Jalan Dr. Suparno No.61 Grendeng Purwokerto Jawa Tengah \\ *email: hartono0606@unsoed.ac.id
}

\begin{abstract}
Abstrak - Potensi energi matahari yang berupa kalor dapat digunakan untuk berbagai kebutuhan, antara lain untuk pengeringan, proses destilasi air laut, atau sebagai pamanas water heater. Optimalisasi media penyerap kalor perlu dilakukan guna meningkatkan kemampuannya. Salah satu variabel yang berpengaruh pada kemampuan penyerapan kalor adalah nilai kalor jenis (c). Keberadaan unsur logam di dalam pasir perlu diteliti untuk mengetahui kemampuannya dalam meningkatkan penyerapan kalor. Kehadiran pasir besi pada campuran bahan pembuat mortar sebagai media penyerap kalor perlu diteliti. Penelitian ini dilakukan secara eksperimental dengan membuat 10 kelompok sampel mortar. Kelompok sampel dibedakan oleh komposisi campuran pasir sungai dan pasir besi yang digunakan sebagai bahan utama. Variasi campuran dibuat dengan perbandingan massa antara pasir sungai dengan pasir besi sebagai berikut: 100:0; 90:10; 80:20; 70:30; 60:40: 50:50; 40:60; 30:70; 20:80 dan 10:90. Sampel mortar yang diuji dibuat dengan ukuran $(2 \mathrm{x} 1 \mathrm{x} 1) \mathrm{cm}^{3}$. Pengujian dilakukan menggunakan kalorimeter bomb. Hasil pengujian diperoleh nilai kalor jenis terendah sebesar $1359,08 \mathrm{~J} / \mathrm{kg}^{\circ} \mathrm{C}$ pada sampel dengan perbandingan campuran pasir sungai dan pasir besi 60:40. Sementara nilai kalor jenis tertinggi pada sampel tanpa pasir besi (100:0) dengan nilai 3555,76 J/kg ${ }^{\circ} \mathrm{C}$. Berdasarkan hasil pengujian, penambahan pasir besi dapat menurunkan kalor jenis pada media mortar.
\end{abstract}

Kata kunci: penyerap kalor, kalor jenis, pasir besi, mortar.

Abstract - Solar energy is an inexhaustible resource for diverse needs, some of which are drying, sea-water destillation, and water heating. Heat absorbing medium is an important component in such processes, and thus needs to be optimized for desirable performance. One parameter that has significant effect on the heat absorbance of absorbing media is specific heat (c). The presence of metal elements in mortar mix that constitute a heat absorbing medium was investigated. Particularly, the presence of iron-sand in mortar mix was experimentally investigated by preparing 10 groups of mortar mix. Each group is separated by its corresponding mixture composition of river-sand and iron-sand as primary materials. The variation of mixture was prepared with the ratio of river-sand and iron-sand of: 100:0; 90:10; 80:20; 70:30; 60:40: 50:50; 40:60; 30:70; 20:80 and 10:90. Each of the mortar samples, $(2 \times 1 \times 1) \mathrm{cm} 3$ in size, is examined using a bomb calorimeter. The measurements reveal that the lowest specific heat is $1359,08 \mathrm{~J} / \mathrm{kg}^{\circ} \mathrm{C}$, which results from the sample with mixture ratio of river sand and iron sand of 60:40. The highest specific heat, 3555,76 J/kgoC in value, is shown by the sample that has no iron-sand (100:0 ratio). This shows that the addition of iron-sand lowers the specific heat of the mortar media.

Key words: heat absorber, specific heat, iron sand, mortar

\section{PENDAHULUAN}

Matahari merupakan salah satu sumber energi terbarukan yang sangat melimpah. Pancaran gelombang elektromagnetik dari matahari dapat mencapai 75,3 juta $\mathrm{W} / \mathrm{m}^{2}$. Intensitas radiasi yang diterima pada bagian terluar atmosfir mencapai $1360 \mathrm{~W} / \mathrm{m}^{2}$, pengurangan energi ini akibat jarak yang sangat jauh antara matahari ke atmosfer bumi. Energi sebesar ini tidak seluruhnya mencapai permukaan bumi, karena adanya hambatan dan penyerapan sehingga hanya $50 \%$ nya yang sampai pada permukaan bumi [1].
Wilayah negara Indonesia sebagian besar mendapatkan paparan matahari dengan jumlah yang sangat melimpah. Potensi energi matahari rata-rata di Indonesia mencapai $4,8 \mathrm{kWh} / \mathrm{m}^{2}$ [2]. Potensi energi matahari yang berupa kalor dapat digunakan untuk berbagai hal, antara lain sebagai sarana pengeringan, untuk membantu proses penguapan pada desalinasi atau destilasi air laut, atau sebagai pamanas water heater. Pemanfaatan energi matahari untuk kebutuhan tersebut membutuhkan media yang mempunyai kemampuan menyerap energi semaksimal mungkin. 
Berbagai upaya sudah dilakukan untuk mengoptimalkan penyerapan energi panas matahari. Upaya optimalisasi penyerapan kalor sudah dilakukan melalui berbagai riset dengan mengkaji berbagai material. Banyak bahan yang telah diteliti untuk keperluan ini, seperti penggunakan sekam padi sebagai media isolator kalor. Sekam padi yang mempunyai nilai konduktivitas yang rendah dapat digunakan sebagai media untuk mempertahankan kalor [3]. Hal serupa juga pernah dilakukan namun menggunakan bahan campuran yang berbeda, yaitu partikel tongkol jagung. Ukuran partikel tongkol jagung mempengaruhi nilai konduktivitas termalnya [4]. Penggunaan pasir sebagai media penyerap kalor juga sudah dilakukan oleh sebagian masyarakat, yaitu sebagai media penggoreng kerupuk. Sesuai dengan hasil penelitian, ukuran partikel pasir juga mempengaruhi kecepatan perambatan kalor [5].

Penggunaan material pasir sebagai media penyerap kalor perlu diteliti lebih lanjut mengingat kemampuannya dalam menerima dan mempertahankan kalor yang diserap. Pasir besi merupakan pasir alam yang mempunyai kandungan unsur logam di dalamnya. Pasir di sekitar pantai Binangun Cilacap mempunyai potensi pasir besi yang cukup melimpah. Keberadaan unsur logam di dalam pasir perlu diteliti untuk mengetahui kemampuannya dalam menyerap dan mempertahankan kalor. Diharapkan kehadiran pasir besi dapat meningkatkan nilai konduktivitas termal dan menurunkan nilai kalor jenis pada media penyerap kalor. Semakin besar nilai konduktivitas termal suatu material maka akan semakin besar kemampuannya dalam menyalurkan energi kalor. Semakin kecil nilai kalor jenisnya akan semakin cepat meningkatkan temperaturnya. Hal ini tentu dapat dimanfaatkan untuk menyerap energi matahari lebih optimal. Oleh karena itu, perlu dilakukan penelitian terkait dengan pembuatan media penyerap kalor dengan perbandingan yang tepat menggunakan campuran pasir sungai dan pasir besi.

Kalor jenis material menunjukkan kemampuan suatu material untuk merubah temperaturnya setiap mengalami perubahan kalor. Kemampuannya untuk menaikkan temperatur ketika mendapatkan tambahan kalor mempunyai peran yang sangat penting dalam konservasi energi. Secara teoritik, sejumlah kalor yang diterima oleh suatu material akan digunakan untuk melakukan perubahan temperatur sesuai dengan persamaan berikut:

$$
Q=m c \Delta T \text {, }
$$

dengan $Q$ merupakan kalor yang diterima material (joule), m merupakan massa dari material $(\mathrm{kg}), c$ menyatakan kalor jenis dari material $\left(\mathrm{J} / \mathrm{kg}^{\circ} \mathrm{C}\right)$ dan $\Delta T$ merupakan perubahan temperatur yang terjadi $\left({ }^{\circ} \mathrm{C}\right)$.

Berdasarkan pada persamaan (1), material dikatakan mempunyai kalor jenis yang besar apabila perubahan temperaturnya sangat kecil untuk jumlah kalor yang diterima. Hal yang sebaliknya, material yang mempunyai kalor jenis kecil akan menghasilkan perubahan temperatur yang besar untuk sejumlah kalor yang sama. Hal ini dapat digunakan sebagai dasar untuk menentukan material atau bahan yang akan digunakan sebagai media penyerap kalor. Berdasarkan pada persamaan (1), maka perancangan media penyerap kalor sebaiknya memilih material yang mempunyai kalor jenis kecil.

\section{METODE PENELITIAN}

Tahap pertama yang dilakukan pada penelitian ini sebelum membuat sampel adalah memisahkan pasir besi dari pasir pantai yang sudah disiapkan. Pemisahan pasir besi dilakukan menggunakan magnet permanen. Pasir yang menempel pada magnet permanen dipisahkan sebagai bahan campuran untuk membuat sampel mortar. Langkah berikutnya adalah membuat sampel mortar menggunakan campuran bahan pasir sungai, pasir besi, semen dan air. Mortar dibuat dalam 10 kelompok sampel dengan perbandingan pasir sungai dan pasir besi sebagai berikut: 100:0; 90:10; 80:20; 70:30; 60:40: 50:50; 40:60; 30:70; 20:80 dan 10:90. Kelompok sampel ini selanjutnya dikodekan berturut-turut dengan kode $\mathrm{M}-0, \mathrm{M}-1, \mathrm{M}-2, \mathrm{M}-$ 3, M-4, M-5, M-6, M-7, M-8 dan M-9. Bahan semen dan air yang digunakan pada setiap kelompok sampel dibuat tetap. Sampel mortar pada cetakan awal dibuat dengan ukuran $(6 \mathrm{x} 4 \mathrm{x}$ 1) $\mathrm{cm}^{3}$. Pembuatan sampel dilakukan untuk setiap kelompok sampel dengan perlakuan yang sama, yaitu waktu pengadukan dan pengeringan. Adonan mortar dituang pada cetakan yang sudah disiapkan. Setiap kelompok sampel dicetak sebanyak 5 buah.

Mortar yang sudah dicetak dikeringkan secara alami dengan cara meletakkan pada tempat yang terbuka dengan aliran udara cukup. Hal ini dilakukan agar mortar mengering secara perlahan sehingga tidak pecah. Seluruh sampel yang sudah mengering dipotong dengan ukuran 
$(2 \times 1 \times 1) \mathrm{cm}^{3}$. Ukuran ini disesuaikan dengan ukuran kalorimeter bomb.

Tahap pengujian dilakukan terhadap seluruh kelompok sampel. Sebelum melakukan pengujian, memastikan ukurannya seragam untuk semua sampel. Memastikan ukuran dilakukan dengan mengukur setiap sampel satu demi satu. Langkah berikutnya setelah memastikan ukurannya seragam adalah menimbang seluruh sampel untuk mendapatkan massa dari setiap sampel uji.

Tahapan berikutnya adalah menguji kalor jenis menggunakan kalorimeter bomb. Sampel dimasukkan dalam tabung pemanas, selanjutnya dipanaskan sampai mencapai suhu tertentu. Sampel yang sudah dipanaskan dalam tabung pemanas dikeluarkan dengan cara melepaskan penahan dan menampung sampel dalam tabung kedua yang sudah diisi dengan air dan terukur suhunya. Perubahan suhu pada tabung ini diukur sampai mencapai suhu kesetimbangan. Proses ini ditunggu sampai mencapai suhu kesetimbangan. Suhu kesetimbangan dicapai manakala suhu dalam tabung isolator sudah stabil. Perulangan pengukuran untuk setiap kelompok sampel dilakukan sebanyak 8 kali. Penentuan nilai kalor jenis menggunakan persamaan (1) dengan menetapkan nilai kalor jenis air yang digunakan sebesar $4200 \mathrm{~J} / \mathrm{kg}^{\circ} \mathrm{C}$. Perhitungan dilakukan untuk seluruh data hasil pengujian. Massa air yang digunakan rata-rata 100 gram.

\section{HASIL DAN PEMBAHASAN}

Kondisi awal sampel mortar dalam cetakan seperti dtunjukkan pada Gambar 1. Seluruh sampel masih dalam cetakan dalam proses pengeringan. Proses pengeringan dalam penelitian ini membutuhkan waktu selama 14 hari. Sampel yang sudah mengering dipotong

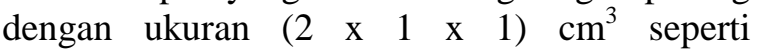
ditunjukkan pada Gambar 2. Pengujian kalor jenis sampel dilakukan pada suhu kamar. Sampel yang sudah diurutkan sesuai dengan kode diuji satu demi satu. Data hasil pengujian rata-rata dari 8 kali perulangan untuk semua kelompok sampel seperti ditunjukkan pada Tabel 1.

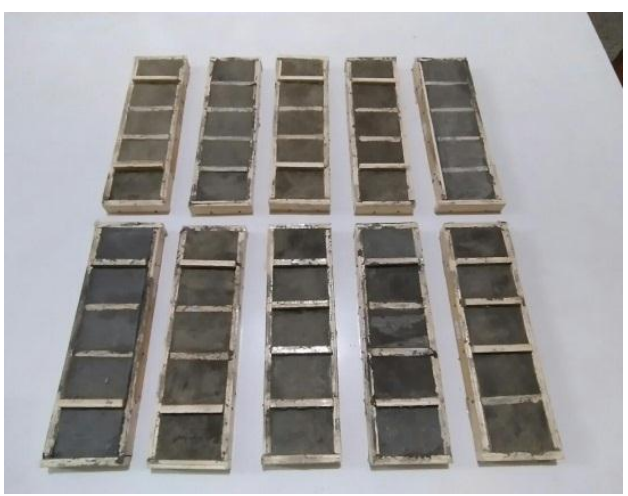

Gambar 1. Sampel mortar tercetak, terdiri dari 10 kelompok sampel

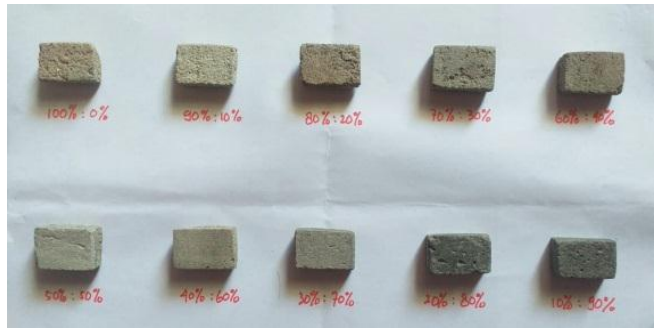

Gambar 2. Potongan mortar dari 10 kelompok sampel.

Tabel 1. Data hasil pengujian kalor jenis sampel mortar

\begin{tabular}{|c|c|c|c|c|c|c|c|}
\hline $\begin{array}{c}\text { Kode } \\
\text { sampel }\end{array}$ & $\begin{array}{c}\mathrm{m}_{\text {mortar }} \\
\text { (g) }\end{array}$ & $\begin{array}{c}m_{\text {air }} \\
\text { (g) }\end{array}$ & $\mathrm{T} 1\left({ }^{\circ} \mathrm{C}\right)$ & $\mathrm{T} 2\left({ }^{\circ} \mathrm{C}\right)$ & $\operatorname{Tc}\left({ }^{\circ} \mathrm{C}\right)$ & $\begin{array}{c}\text { c air } \\
\left(\mathrm{J} / \mathrm{kg}^{\circ} \mathrm{C}\right)\end{array}$ & $\begin{array}{l}\text { c mortar } \\
\left(\mathrm{J} / \mathrm{kg}^{\circ} \mathrm{C}\right)\end{array}$ \\
\hline M-0 & 10,53 & 101,06 & 81,13 & 24,88 & 29,38 & 4200 & 3506,278 \\
\hline M-1 & 9,98 & 101,09 & 80,00 & 24,50 & 28,38 & 4200 & 3194,571 \\
\hline M-2 & 10,35 & 100,91 & 81,25 & 25,25 & 28,75 & 4200 & 2730,524 \\
\hline$M-3$ & 12,80 & 101,20 & 82,63 & 24,25 & 27,88 & 4200 & 2198,587 \\
\hline$M-4$ & 12,88 & 101,13 & 81,63 & 24,88 & 28,13 & 4200 & 2003,456 \\
\hline$M-5$ & 13,52 & 101,13 & 78,63 & 25,00 & 27,75 & 4200 & 1698,169 \\
\hline$M-6$ & 13,99 & 100,78 & 82,13 & 24,13 & 26,63 & 4200 & 1362,673 \\
\hline M-7 & 14,31 & 100,97 & 80,88 & 24,88 & 27,38 & 4200 & 1384,545 \\
\hline$M-8$ & 15,74 & 100,78 & 82,88 & 22,75 & 26,13 & 4200 & 1599,817 \\
\hline M-9 & 15,17 & 101,12 & 83,88 & 24,75 & 28,25 & 4200 & 1762,001 \\
\hline
\end{tabular}




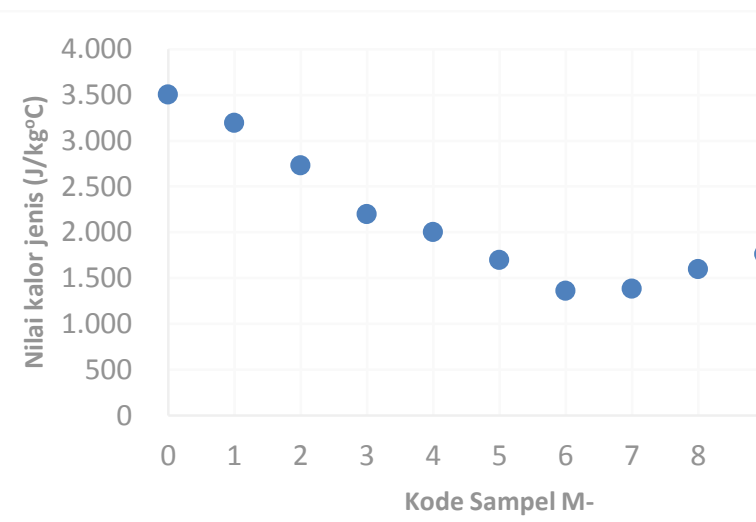

Gambar 3. Hasil uji nilai kalor jenis dari sampel mortar

Berdasarkan pada data hasil pengujian sebagaimana ditunjukkan pada Tabel 1 ataupun Gambar 3, terlihat bahwa penambahan pasir besi pada campuran bahan pembuat mortar berdampak pada penurunan nilai kalor jenisnya. Penurunan nilai kalor jenis seiring dengan penambahan pasir besi. Nilai kalor jenis terendah dicapai pada sampel M-6, yaitu pada perbandingan pasir sungai dan pasir besi (40:60)\%. Penambahan pasir besi yang lebih besar dari $60 \%$ terlihat mulai meningkat nilai kalor jenisnya.

Campuran bahan mortar pada sampel M-7, M-8 dan M-9 setelah dilakukan pengadukan menghasilkan adonan yang relatif lebih encer dibandingkan dengan campuran yang lain. Semakin banyak pasir besi dalam campuran semakin encer adonan mortar yang diperoleh. Hal ini dikarenakan pasir besi tidak banyak menyerap air. Kondisi yang seperti ini menyebabkan adanya pori-pori pada saat sampel sudah mengering. Sampel M-9 terlihat paling poros jika dibandingkan dengan sampel yang sebelumnya, seperti yang terlihat pada Gambar 4. Keberadaan pori yang terisi udara menyebabkan penyerapan kalor pada sampel mengalami penurunan yang ditunjukkan dengan meningkatnya nilai kalor jenisnya. Analisis ini perlu diperkuat dengan melakukan pengujian SEM untuk melihat struktur dari sampel.

\section{KESIMPULAN}

Pembuatan sampel mortar sebagai media penyerap kalor sudah dibuat dan diuji terhadap nilai kalor jenisnya. Berdasarkan pada hasil pengujian dapat disimpulkan bahwa penambahan pasir besi terhadap pasir sungai sebagai bahan pembuat media penyerap kalor dapat meningkatkan kemampuannya dalam menyerap kalor. Hal ini didasarkan pada nilai kalor jenis yang semakin kecil seiring dengan penambahan pasir besi. Namun demikian, pada batas tertentu penambahan pasir besi akan menurunkan kemampuannya dalam menyerap kalor. Sampel dengan perbandingan campuran 40:60 merupakan sampel terbaik dalam menyerap kalor..

\section{UCAPAN TERIMA KASIH}

Pada kesempatan ini penulis mengucapkan terimakasih kepada pihak-pihak yang sudah membantu terlaksananya penelitian ini. Penulis mengucapkan terimakasih kepada

1. LPPM Universitas Jenderal Soedirman yang sudah menugaskan dan memberikan pembiayaan terhadap penelitian ini.

2. Laboratorium Elektronika Instrumentasi dan Geofisika Jurusan Fisika FMIPA Unsoed yang sudah menyediakan fasilitas untuk penelitian.

3. Achmad Nur Susbiantoro yang sudah membantu pengujian sampel.

\section{PUSTAKA}

[1] Nadia Handayani, Taufik Fajar Nugroho, dan Sutopo Purwono Fitri, "Analisa Kinerja Termal Solar Apparatus Panel pada Alat Destilasi Air Payau dengan Sistem Evaporasi Uap Tenaga Matahari Menggunakan CFD”, Jurnal Teknik Pomits, 3(2) (2014) 2301 - 9271.

[2] Saipul Hamdi, "Mengenal Lama Penyinaran Matahari sebagai Salah Satu Parameter Klimatologi”, Berita Dirgantara, 15(1) (2014) 7 - 16.

[3] Hary Wibowo, Khairul Muhajir, Toto Rusianto, Ellyawan Arbintarso, Jurnal Teknologi Technoscientia, 1(1) (2008) 29 - 34.

[4] Nanda Pratama, Djusmaini Djamas, Yenni Darvina, "Pengaruh Variasi Ukuran Partikel Terhadap Nilai Konduktivitas Termal pada Partikel Tongkol Jagung, Pillar Of Physics, 7 (2016) 25 - 32.

[5] Lina Nirwana, Muh.Rais, Jamaluddin P, "Konduktivitas Termal Pasir Kali Sebagai Media Penghantar Panas pada Proses Penyaraian Kerupuk, Jurnal Pendidikan Teknologi Pertanian, 3 (2017) S182 S196 